\title{
More variable tropical climates have a slower demographic growth
}

\author{
Pierre Camberlin* \\ Centre de Recherches de Climatologie, Département de Géographie, UMR 5210 Université de Bourgogne/CNRS, \\ 6 Boulevard Gabriel, 21000 Dijon, France
}

\begin{abstract}
A classical approach to assess the amplitude of rainfall variations is based on the coefficient of variation. Using worldwide station data for the twentieth century, an alternative method, involving the development of a polynomial fit, was shown to be more relevant to semi-arid climates. The results singularised the tropical and subtropical regions, whose amplitude of interannual rainfall variability was larger than that of the extra-tropical regions, for a given mean rainfall value. However, the tropical belt also showed large contrasts between highly variable climates - corresponding mainly to regions where the sea-surface temperature forcing is strongest-and more steady climates. A separate analysis documented the relationship between the amplitude of rainfall variations and human demography. Population densities did not show any systematic decline with increasing variability. However, in the tropics, there was often a coincidence between reduced demographic growth and high rainfall variability. This smaller demographic growth may result from both reduced natural growth (especially enhanced mortality) and out-migration from regions affected by strong rainfall variations, as evidenced from a number of African cases studies. In contrast, tropical regions with a fast-growing population had on average a lower rainfall variability.
\end{abstract}

KEY WORDS: Precipitation · Variability · Demographic growth · Population density

\section{INTRODUCTION}

Climate variations around the mean are unequal around the world. Some regions are known to be repeatedly affected by climatic hazards that have devastating impacts on the local population and economy. In some cases, the damaging effects of climatic hazards can be attributed to a high vulnerability of the local communities. In other cases, it is the intensity of the climatic event itself that accounts for much of the devastation, which can be extensive even in areas having a high level of preparedness. Tropical cyclones and droughts provide numerous examples illustrating both situations. However, in several instances, and in the long run, it is difficult to assess the respective parts played by vulnerability and hazard characteristics or repetitiveness in the impacts of climate variability. For instance, while the direct consequences of a single powerful climatic event over a given area are fairly easy to assess, it is much more challenging to have both a global and a long-term view of the relationship between year-to-year climate fluctuations and human societies (Ribot et al. 1996, Wisner et al. 2003). In one of the few studies available, Brown \& Lall (2006) found a statistically significant relationship between greater rainfall variability (especially intra-annual) and lower per capita Gross Domestic Product, in a comparison taking into account 163 countries over the period 1979-2004.

Comparing the amplitude of climate variations across regions is often made difficult by the unsuitable criteria used to describe climate variability. Rainfall is particularly problematic, due to the fact that it has a skewed statistical distribution, with numerous records of zero precipitation in drylands - and sometimes even in wetter areas - depending on the timescale. Yet, in much of the tropics and subtropics, its variability strongly impacts human communities. Spatial com- 
parisons of rainfall variability - for instance using the coefficient of variation $(\mathrm{CV})$, generally regarded as a standard criterion - tend to be biased by this statistical distribution issue. A first objective of this study was therefore to document spatial patterns in the amplitude of rainfall variations, by considering an alternative definition of interannual rainfall variability. Conrad (1941) and Nicholls (1988) calculated relative variability as the mean of the absolute deviations from the long-term mean (LTM), expressed as a percentage of the LTM. This definition, like the CV (Nicholls \& Wong 1990), tends to make drier stations display a higher variability. Dewar \& Wallis (1999) further analysed the patterns of rainfall variability, using the 0.1 quantile (QU10), or the proportion of mean annual rainfall expected in the driest year out of $10 \mathrm{yr}$, as the measure of variability. A nonlinear regression was fitted to the relationship between QU10 and mean annual rainfall. They found strong spatial contrasts between coherent regions of high and low rainfall variability. However, their analysis was restricted to the tropics and near tropics. I therefore extended their results to the global scale, using a rainfall variability index based on standard deviation (SD), at both annual and monthly time scales.

Assessing how regional differences in the level of rainfall variability impact societies is a delicate task. These impacts actually take many different forms and depend on the economic activities, incomes, technical knowledge and coping mechanisms developed by these societies. Since developing countries are predominantly in the tropics, and rainwater availability is a major climatic constraint in the tropics, I hypothesised that the relationship between rainfall amplitude and human activities is stronger in this zone than elsewhere. To verify this assumption, this study focused on demography. The aim was to assess whether either population densities or demographic growth around the world have any relationship with the above defined rainfall variability index.

Le Blanc \& Perez (2008) noted that in sub-Saharan Africa, mean annual rainfall and human density are strongly correlated below $900 \mathrm{~mm}$ of annual rainfall. They suggested that the variability of rainfall is also a critical determinant of local carrying capacities, but they did not test this hypothesis. Small \& Cohen (2004) found that the global distribution of population is much more dependent on physiographic (altitude, distance to water bodies) than on climatic parameters, although population densities tend to be highest at intermediate (around $1000 \mathrm{~mm}$ ) annual precipitation amounts and in highly seasonal (e.g. monsoonal) precipitation regimes. Again, they did not consider population change. This aspect has been dealt with in regional case studies analysing the demographic impacts of individual cli- matic hazards. In connection with flooding in 1974, Bangladesh lost about $2 \%$ of its population to famine (Caldwell \& Caldwell 1992, Devereux 2002). Even more pronounced mortality rates (about 7 times higher than in Bangladesh) were found during the 1984-85 drought-related famine in northern Ethiopia (Kidane 1989). Demographic behaviours of Ethiopian rural communities have also been affected by environmental stress and food insecurity, with an increase in outmigration and a reduction in fertility (Ezra 2001). Many regional case studies have suggested that out-migration is a frequent outcome of major climatic events, especially long-lasting droughts (Teklu et al. 1991, Magalhaes 1993, Finan \& Nelson 2001, Haug 2002, Henry et al. 2003, Weiss 2003). However, previous authors have insisted on the diversity of situations in the relationship between drought and migration (Findley 1994, Pedersen 1995, Retaillé 1995). In fact, very few studies have dealt with the possible relationship between population dynamics and climate variability at a global scale. Based on global gridded population maps, Milesi et al. (2005) noted that population growth between 1982 and 1998 was strong in water-limited areas (most tropical regions). They also found significant correlations between El Niño-Southern Oscillation (ENSO), the leading mode of interannual climate variability around the globe, and terrestrial net primary production over $63 \%$ of the world's vegetated surface, mainly in tropical and subtropical areas. However, possible associations between population growth and ENSO variability were not explicitly addressed. Afifi \& Warner (2008) found a statistically significant relationship between environmental degradation and out-migration, based on a selection of countries, although their study did not consider climate variability indicators as such.

At continental and global scales, it is therefore unknown whether there is any discernable effect of climate variability on human occupation and dynamics, a question that I sought to address here by considering the mean amplitude of rainfall variations. After presenting the data (Section 2), a rainfall variability index is defined and analysed in Section 3. A diagnostic on the probable causes of the spatial discrepancies in the amplitude of rainfall variability is also provided. Section 4 then deals with the potential relationships between rainfall variability and demography.

\section{DATA}

The rainfall data used in this study originated from the Global Historical Climate Network (GHCN, Peterson \& Vose 2001). Over 12300 stations were extracted, with monthly precipitation time-series of various lengths, encompassing the period 1901-2005. It was 
not possible to use a fixed period of time for all stations, given the poor data availability during either the first or the second half of the twentieth century for several parts of the world. A minimum period of time of $40 \mathrm{yr}$ was retained (no prior estimation of missing values), and the long-term monthly and annual means and SD were computed. A 40 yr period was judged as sufficient to reflect reasonably well both decadal and yearto-year variability. Note that it is preferable to use station (point) data and not grid-point (areal) averages. Spatial averages tend to reduce the amplitude of interannual variations when they mix stations showing different temporal variations, unless the amplitude is rescaled to that of the individual stations (Osborn \& Hulme 1997, Brohan et al. 2006).

The population data set used in the second part of the study is the Gridded Population of the World, Version 3 (GPWv3), which originated from Columbia University (CIESIN 2005). Gridded population density values were available at a $0.25^{\circ}$ latitude and longitude resolution for the years 1990 and 2000. Population growth rates between these 2 years were also computed. Their accuracy depends on the availability of regular census data. This data set has been used in previous studies dedicated to the relationship between climate patterns and human densities (e.g. Le Blanc \& Perez 2008).

Due to data availability, there was an apparent mismatch between the periods used for assessing rainfall variability (40 yr periods within the years 1901-2005) and demographic growth (1990-2000). However, the aim was not to study the impact of individual climatic events on demographics for a given year. Instead, it was to assess how large the standard climate variability at different locations is and whether it is matched by spatial variations in population densities and general population growth. Additionally, it was verified that the amplitude of interannual variability during 19902000, at the stations having data for this decade, was not strongly different from that computed from longterm time series.

\section{RAINFALL VARIABILITY INDEX: DEFINITION AND SPATIAL PATTERNS}

\subsection{Indicator of rainfall variability}

A common indicator of the amplitude of interannual climate variability is the $\mathrm{CV}$, which is defined as the ratio between the SD and the mean (Longley 1952). Apart from the fact that it cannot be applied to some climate variables like temperature (unless expressed in $\mathrm{K}$ ), its use for 0-bounded climate variables, like precipitation amounts, is questionable. The problem arises when working at short time scales (daily to monthly),

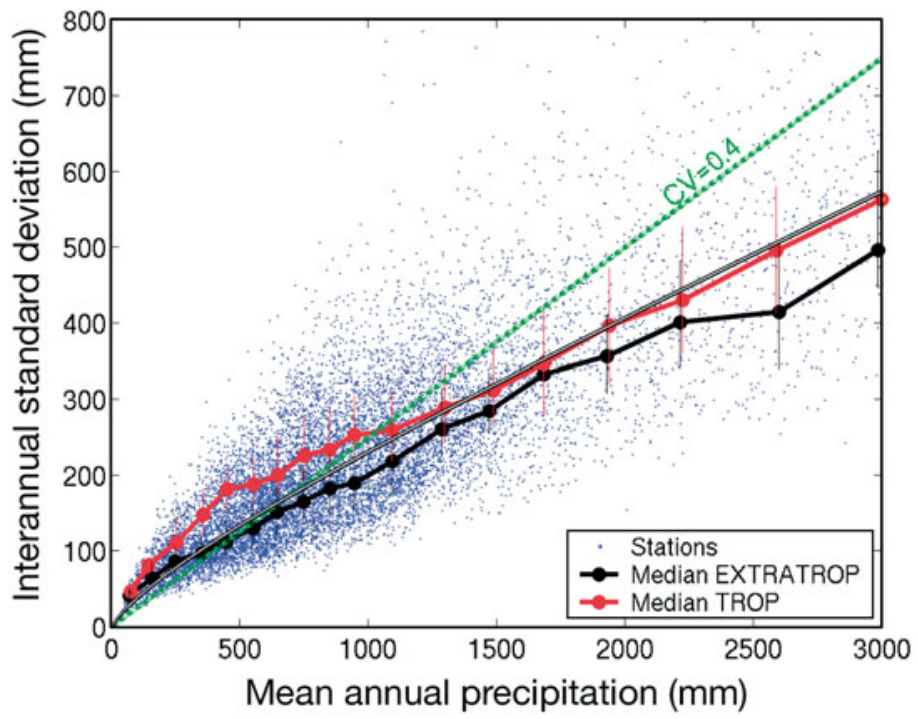

Fig. 1. Interannual variability of annual precipitation, for 12335 stations extracted from the Global Historical Climate Network (GHCN) data base (Peterson \& Vose 2001). Annual rainfall was computed for stations having at least $40 \mathrm{yr}$ of complete data between 1901 and 2005. Coefficient of variation (CV) of 0.4 shown for reference. The red line is the median for tropical stations $\left(23^{\circ} \mathrm{S}\right.$ to $\left.23^{\circ} \mathrm{N}\right)$; the black solid line is the median for all other stations. Vertical bars are the interquartile range of the SD for successive bins of mean annual rainfall. The double thin line shows the polynomial fit used for the computation of the rainfall amplitude index (RAI)

or even at annual time scales in semi-arid environments. When the time series is skewed towards 0 , the $\mathrm{CV}$ draws towards very high values as a result of the division by a very small mean.

Therefore, for an adequate comparison of stations (or seasons), an alternative indicator of precipitation variability must be used. Fig. 1 shows the SDs of annual rainfall, with respect to the mean, at the $12335 \mathrm{GHCN}$ stations across the world. It is evident that there is a strong relationship between SDs and means. However, the relationship is not fully linear (below a mean annual rainfall of about $500 \mathrm{~mm}$, the scatterplot tends to be slightly curved), and the plot is slightly offset with respect to $0 \mathrm{SD}$. There is also a considerable scatter, which indicates that for a given mean, precipitation variations can be either high or low. For instance, both Pendencias (northeastern Brazil) and Copenhagen (Denmark) have a mean annual rainfall close to $600 \mathrm{~mm}$. However, the climate of Pendencias is three times as variable as that of Copenhagen, the 2 stations having SDs at 301 and $94 \mathrm{~mm}$, respectively.

A second-order polynomial best fit was thus empirically adjusted to the scatterplot. The equation is in the form:

$$
\sigma_{\mathrm{e}}=\mathrm{a} 1 \mathrm{x}^{\mathrm{k} 1}+\mathrm{a} 2 \mathrm{x}^{\mathrm{k} 2}+\mathrm{a} 3
$$

where $\sigma_{\mathrm{e}}$ is the estimated SD, $x$ is the mean, and a1, a2, $\mathrm{a} 3, \mathrm{k} 1$ and $\mathrm{k} 2$ are empirically fitted coefficients. Best fit 
coefficients were set to $0.0013,1.52,-2.16,1.43$ and 0.71 for $\mathrm{a} 1, \mathrm{a} 2, \mathrm{a} 3, \mathrm{k} 1$ and $\mathrm{k} 2$, respectively. The polynomial power curve is fairly linear for the wettest stations, and curvilinear for drier environments (Fig. 1). Under dry conditions, the $\mathrm{CV}$ systematically overestimates rainfall variability; for instance, all low-rainfall stations are located above the $0.4 \mathrm{CV}$ line on Fig. 1. It is therefore not convenient to use the $\mathrm{CV}$ to compare the variability of wet and dry stations, since the CV results from a division by a mean value, which tends towards zero, as discussed at the beginning of this section. The polynomial fit is more efficient at differentiating highly/weakly variable stations.

In a second step, the rainfall amplitude index (RAI) was defined as the ratio between the actual SD at each station and the theoretical value $\sigma_{\mathrm{e}}$ obtained from the empirical best fit. Thus, an RAI of 1 at a given station means that the rainfall variability at this station is close to average.

\subsection{Patterns of rainfall variability}

To depict the spatial patterns of rainfall variability, the network of stations was first divided into tropical $\left(23^{\circ} \mathrm{S}\right.$ to $\left.23^{\circ} \mathrm{N}\right)$ and extra-tropical subgroups. For each subgroup, and for successive classes of mean annual rainfall, the SD is shown in Fig. 1. There is a gap between the 2 subgroups, particularly under semi-arid and sub-humid environments (about 250 to $1000 \mathrm{~mm}$ ). In this range, tropical stations display much larger interannual rainfall variability than their extra-tropical counterparts. For a given mean rainfall amount, the SD is 25 to $50 \%$ higher in the tropics than in the extratropics. A possible explanation for this difference could be that extra-tropical stations tend to have rainfall

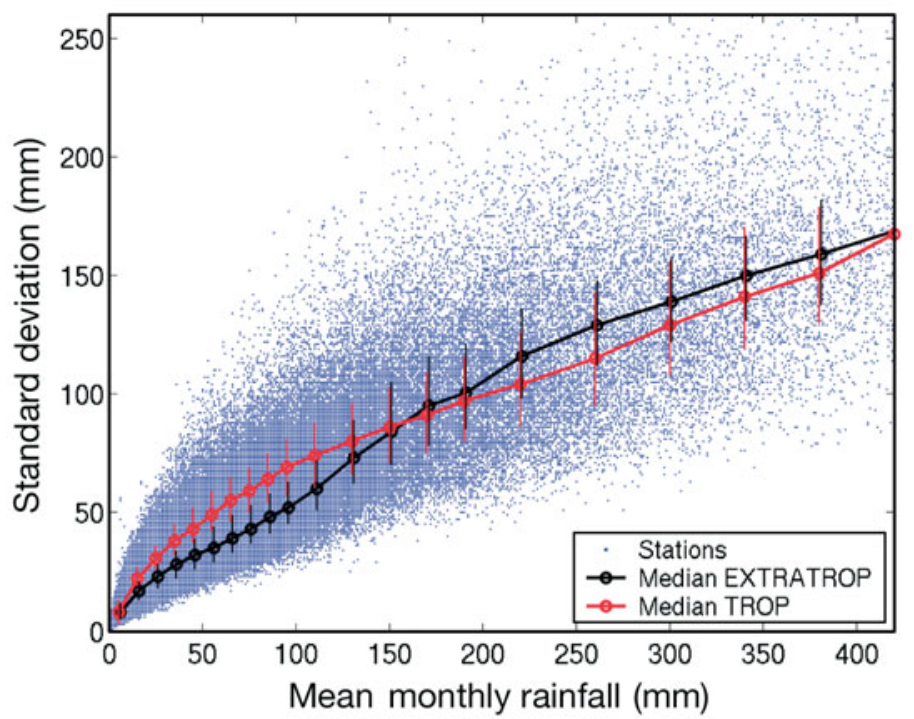

Fig. 2. As in Fig. 1, but for monthly rainfall

scattered over the year and hence a greater chance to compensate a high rainfall amount by a lower one several months later. Reciprocally, in much of the tropics rainfall is concentrated over a well-defined (and sometimes short) rainy season (McGregor \& Nieuwolt 1998). To test whether this hypothesis could explain the higher variability of the tropics, a good way is to consider interannual variability on a monthly basis.

The same scatterplot as in Fig. 1 is thus shown in Fig. 2 for monthly instead of annual rainfall amounts. For mean rainfall between 25 and $125 \mathrm{~mm}$, there is still a discernible difference between tropical and extratropical stations. Variability in the extra-tropics tends to be much lower. The reverse is found above $200 \mathrm{~mm}$, but the difference between the 2 sets of stations is not significant. This is a demonstration that the larger

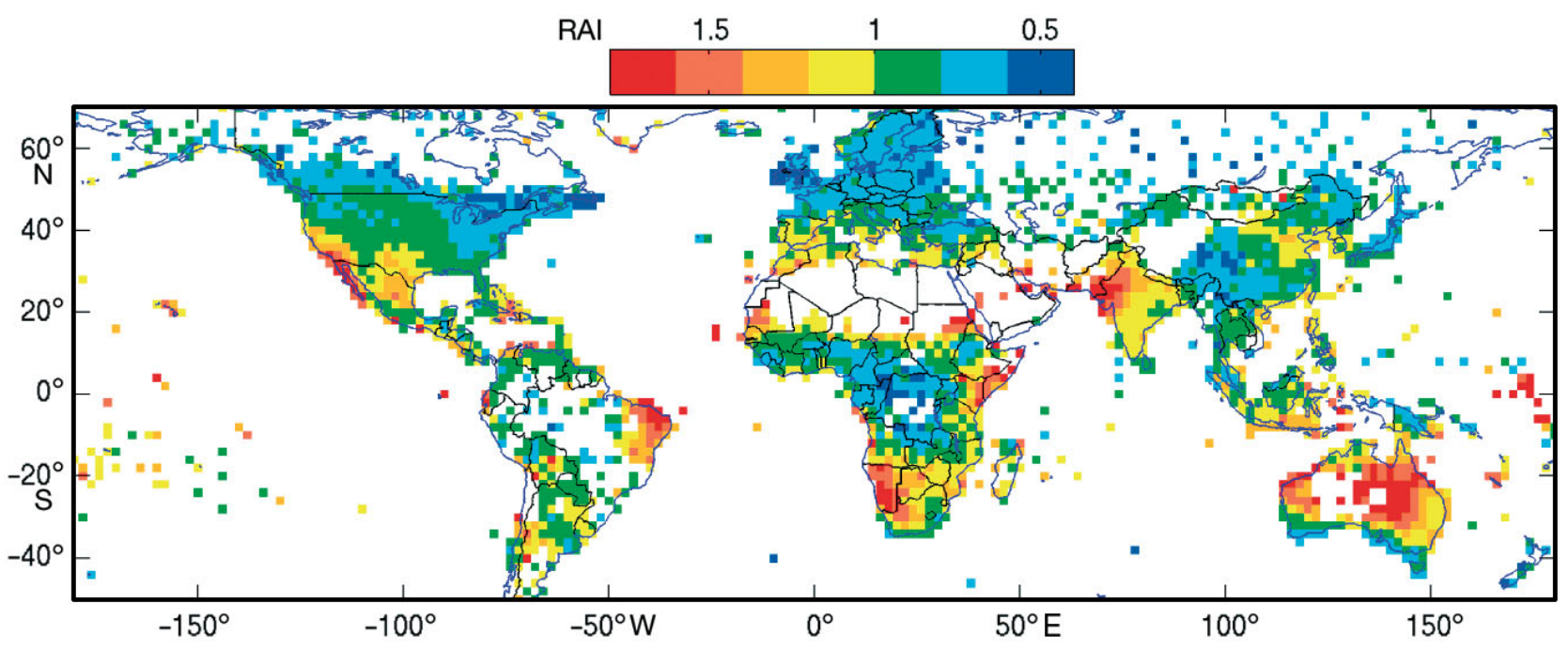

Fig. 3. Rainfall Amplitude Index (RAI) of the interannual variability of annual rainfall amounts 
interannual variations of annual rainfall in the tropics are not an artefact caused by a greater seasonal concentration.

To apprehend the spatial patterns of rainfall variability, the RAI for annual rainfall was mapped (Fig. 3). Besides the overall lower precipitation variability of the middle and high latitudes, the map reveals large contrasts within the tropical zone. Tropical drylands generally display relatively high rainfall variability. However, these areas are not as uniform as the image conveyed by maps of the $\mathrm{CV}$, which exaggerate rainfall variability in drylands. Interannual variability is high in Somalia, Australia and northwestern India, but moderate in parts of the central Sahel. This is contrary to general belief but in accordance with Le Houérou (2006), who noted that Sahelian precipitation is less variable than that of the East African drylands.

An example of the unequal level of rainfall variability is provided by the comparison of 3 stations belonging to the African drylands (Fig. 4). Hombori (Mali), Garissa (Kenya) and Okahandja (Namibia) had a mean annual rainfall between 342 and $376 \mathrm{~mm}$ over the period 1951-2000. However, their RAIs are markedly different. Hombori (RAI = 1.0), in the west African Sahel, exhibits the most reliable rains. Garissa and Okahandja (RAI $=1.6$ at both stations) have experienced annual rainfall in excess of $600 \mathrm{~mm}$ on 7 and 2 occasions, respectively, while at Hombori, this amount was never reached during the same 50 yr. Similarly, rainfall below $120 \mathrm{~mm}$ has been recorded at least twice at the 2 former stations, but never at Hombori. Although crops in the Sahel have been impacted by drier conditions starting from the 1970s, rain-fed agriculture

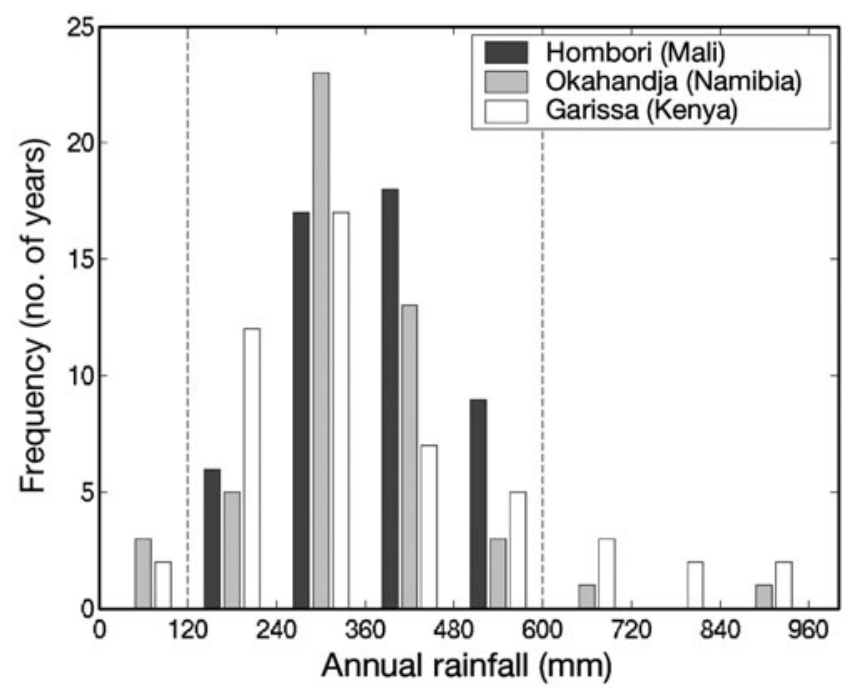

Fig. 4. Frequency distribution of annual rainfall amounts (1951 to 2000) at 3 semi-arid African locations: Hombori (Mali, mean rainfall $376 \mathrm{~mm}$ ), Okahandja (Namibia, $342 \mathrm{~mm}$ ) and Garissa (Kenya, $370 \mathrm{~mm}$ ). Dashed lines: reference rainfall amounts given in Section 3.2

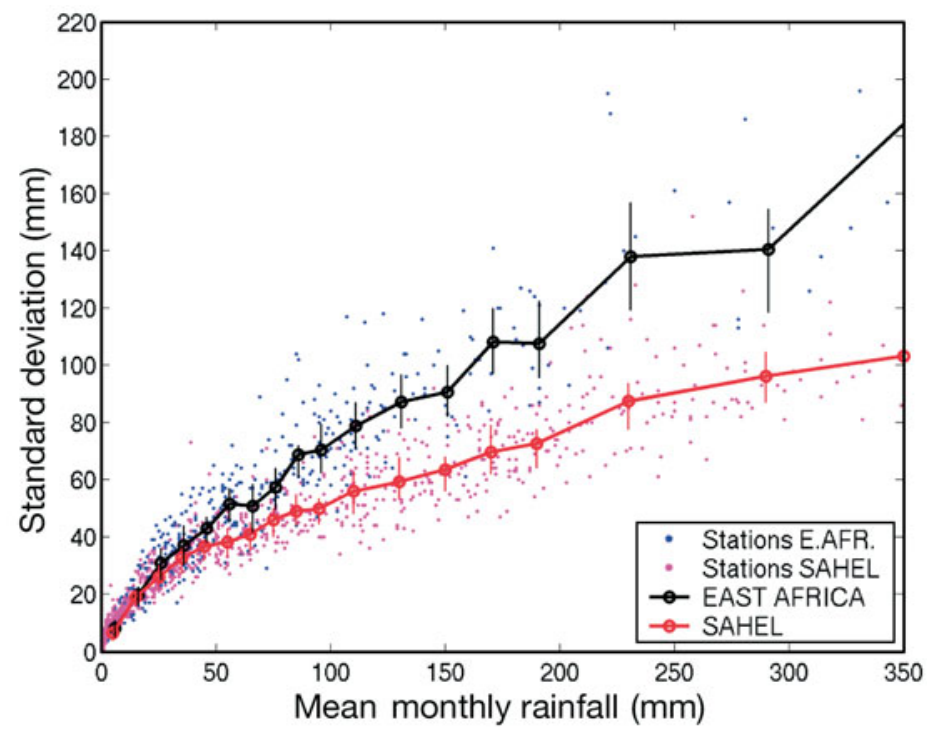

Fig. 5. As in Fig. 2, but for all stations from East Africa $\left(5^{\circ} \mathrm{N}-5^{\circ} \mathrm{S}\right.$, $\left.35-45^{\circ} \mathrm{E}\right)$ and the Sahel $\left(11-19^{\circ} \mathrm{N}, 20^{\circ} \mathrm{W}-20^{\circ} \mathrm{E}\right)$

is commonly practised in the region even at relatively low mean annual rainfall amounts, whereas other parts of the tropics (including East Africa) with similar mean annual rainfall do not generally bear crops (Ellis \& Galvin 1994, Le Houérou 2006). Rainfed agriculture can be practised in the Sahel partly because the rainfall is concentrated over a few months, and also because of a lower interannual variability of the rains. A comparison of monthly rainfall variability between Eastern and Sahelian Africa confirms that above a mean rainfall of $50 \mathrm{~mm}$, there are much larger interannual variations in East Africa (Fig. 5). Ellis \& Galvin (1994) noted that this higher rainfall variability in East Africa induces non-equilibrium ecosystem dynamics, thereby making some concepts of agricultural and natural resource management unsuitable. Additionally, it increases the risk of crop losses and therefore restricts the area devoted to rain-fed agriculture.

Reciprocally, wetter climates do not always have the regularity suggested by CV maps. For instance, parts of southern Indonesia, southern Mozambique and the central Pacific islands exhibit quite large interannual rainfall variations. By contrast, most of the extra-tropics and some tropical regions like southern China, the Congo Basin and much of the Amazon Basin display low RAI values (Fig. 3).

On the whole, these patterns closely resemble those found by Dewar \& Wallis (1999). They noted that the geographical patterning of rainfall variability for the region they studied $\left(30^{\circ} \mathrm{S}\right.$ to $\left.30^{\circ} \mathrm{N}\right)$ was far from random. They found that oceanic islands have a strong tendency toward high variability. As displayed in the present study (Fig. 3), they also noted, like Conrad (1941), that most high variability regions are located 
near coasts, and continental interiors tend to be areas of reduced variability. This is evident in Africa, including in the Sahelian belt (see the difference between coastal Senegal/Mauritania and inland stations in Mali, Niger or Chad, at the same latitude). The delineation of the extra-tropical regions having a lower rainfall variability is also consistent with Nicholls \& Wong (1990), who noted a decrease in rainfall variability with latitude.

A thorough explanation of the causes of these spatial patterns in climate variability is not the topic of this study. However, the sensitivity to sea-surface temperature (SST) variations plays a major role. Regions with a higher interannual variability are often those where large-scale ocean-atmospheric modes of climatic variability have the strongest impact. In particular, ENSO strongly affects rainfall amounts over parts of Indonesia, Australia and some Pacific islands (Ropelewski \& Halpert 1987). The latter exhibit abnormally high interannual variability in precipitation. The ENSO influence is combined with that of Walker-type, largescale circulation anomalies across the Indian Ocean to explain the large rainfall variability also experienced in East Africa (Philippon et al. 2002, Black et al. 2003, Hastenrath \& Polzin 2003). By contrast, precipitation over the Congo Basin is quite insensitive to global SSTs in general, and ENSO in particular (Camberlin et al. 2001, Friederichs \& Paeth 2006). Nicholls \& Wong (1990) demonstrated that low latitude stations display a greater rainfall variability when they have a strong relationship with ENSO. Peel et al. (2002) found that the $\mathrm{CV}$ of annual precipitation was 5 to $25 \%$ higher in 'ENSO' than in 'non-ENSO' zones, after having stratified the stations according to Köppen climate types. Koster et al. (2000) published maps of the rainfall variance explained by SST variability, based on ensemble simulations performed with the NASA Goddard Earth Observing System-Climate atmospheric model. There are coincidences with Fig. 3 (e.g. strong SST forcing and high rainfall variability in northeastern Brazil and western Sahel), but some areas known from the observation to be strongly affected by SST variations, such as East Africa, were not identified as such in the simulations by Koster et al. (2000), probably due to model deficiencies.

On the whole, there is a strong indication that sensitivity to SST variability explains much of the spatial inequalities in rainfall variability. In extra-tropical regions, the weaker SST forcing reduces the seasonal persistence of monthly rainfall anomalies, hence a damped interannual variability compared to those regions whose climate is influenced by highly persistent modes of variability, such as ENSO. Other factors may also contribute to the spatial discrepancies. For instance, some regions with relatively high rainfall variability, without necessarily being drylands, are those affected by tropical cyclones, such as part of the Caribbean, southern Mozambique, Viet Nam and part of the Philippines. However, not all cyclonic areas are affected, and the effect is smaller than that associated with the SST control on rainfall. Contrary to higher latitude regions, where "oceanic" climates tend to have a dampening role on rainfall variations, the ocean impact at low latitudes (either direct or indirect) is in the direction of enhanced rainfall variability.

\section{RELATIONSHIP WITH DEMOGRAPHIC VARIABLES}

\subsection{Population density}

As discussed in Section 1, the effects of rainfall variability on demography are poorly known. An initial question is whether a high climate variability is detrimental to those inhabitants exposed to it. Although the above African examples suggest a potential effect of rainfall variability on land use and farming systems, it remains to be assessed whether population densities are impacted at the global scale. Gridded population densities for the year 2000 , at a $0.25^{\circ}$ latitude and longitude resolution, were extracted from the Columbia University GPWv3 data set. RAI was plotted for different classes of population density (Fig. 6). Although rainfall variability tended to be slightly higher in tropical areas with a low population density, on the whole, the relationship between density and variability was not significant, either for the tropics or the extra-

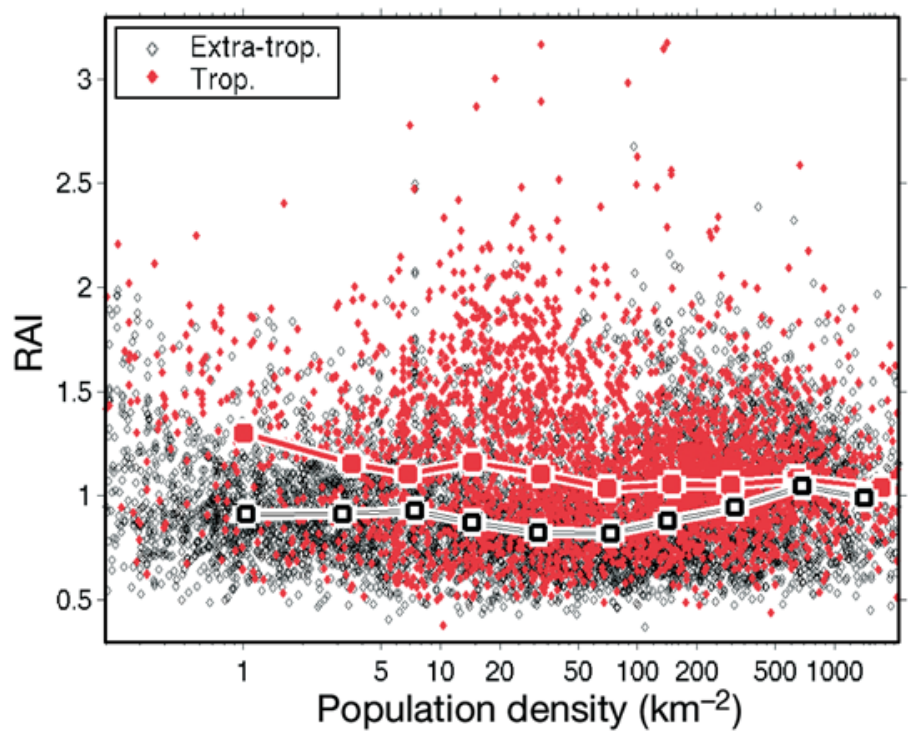

Fig. 6. Relationship between population density (people $\mathrm{km}^{-2}$, log scale; in 2000) and the rainfall amplitude index (RAI). The squares correspond to the mean values obtained for successive density classes. Empty (filled) symbols correspond to extra-tropical (tropical) locations 
tropics. This was still true when the data were stratified according to the mean annual rainfall (not shown). Some relatively dry areas experiencing a high variability (Fig. 2) showed either high (northeastern Brazil, northwestern India) or low (Somalia, Namibia) population densities. Reciprocally, there was a higher rainfall variability in Java than in Thailand and southwestern China, although all of these areas are densely settled.

The absence of any relationship between population densities and precipitation variability, at a global scale, can be interpreted in 2 different ways:

(1) there is an actual disconnection between the 2 features, which means that in high variability areas, societies have often successfully adapted to these more risky environments. Strategies aimed at reducing the impact of precipitation variability, such as irrigation and mixed cropping, may be able to feed a larger number of people, while even in 'low risk' areas, extensive land management systems only tolerate low densities. For instance, agrarian societies in northern Peru have in the past developed social and technological responses to environmental uncertainty (Dillehay \& Kolata 2004).

(2) the impact of rainfall variability on human densities is found at the regional level only, and is masked by other factors at the global scale. In insular Southeast Asia and the western Pacific, Dewar (2003) noted that from west to east, in conjunction with increasing interannual rainfall variability, subsistence systems shift from grain crops to root and tree crops. He suggested that this variability limited the suitability of annual crops and increased dependence on long-lived plants. We can add that annual crops both require and permit higher population densities, thus the associated west to east decreasing population density gradient amplifies the west to east increasing variability gradient. In Africa, there are contrasted subsistence systems between the East and West African drylands. As depicted above, at similar mean annual precipitation amounts, crops are much less common in East Africa, where pastoral, lower-density communities prevail. This contrast reflects the greater (smaller) intra-annual and interannual rainfall variations of East (West) Africa (Ellis \& Galvin 1994). Elsewhere, however, there are numerous examples of relatively high human densities in otherwise high-variability areas, such as northeastern Brazil and parts of India, whereas several low-variability areas, especially in the Amazonian and Congo rainforest, have very low densities. This may overshadow any regional relationships between human density and rainfall variability.

These results on rainfall variability do not imply that human population distribution is disconnected from rainfall. Consistent with Small \& Cohen (2004), global maps of mean annual rainfall and population densities show that below a certain amount, the joint decrease of population densities and precipitation is a recurrent feature around the globe, except in a few cases where exogenous rivers provide water resources in otherwise dry environments. This pattern is particularly obvious in sub-Saharan Africa (Le Blanc \& Perez 2008). Although in some regions (e.g. western Pacific, African drylands) rainfall variability may play a significant part in the contrasting human densities, it is believed that in the long run (present-day densities result from demographic dynamics integrated over a long period of time) and at a global scale, other factors (e.g. natural, political, historical, socio-economic) are overwhelming.

\subsection{Demographic growth}

A similar analysis was carried out by considering recent population dynamics (1990-2000 growth rates; Fig. 7). I found that in the tropics, regions where demographic growth is small, or even negative, often display high interannual rainfall variability (Fig. 7). Although there is some uncertainty about the precision of the population data, the fact that a similar pattern was found for each continent (coloured lines in Fig. 7 depict tropical Africa, tropical Asia and tropical America) is an indication that this result is relatively robust. Several high-variability regions, such as northeastern Brazil, Mauritania and Somalia, actually display a demographic growth slower than that of the other trop-

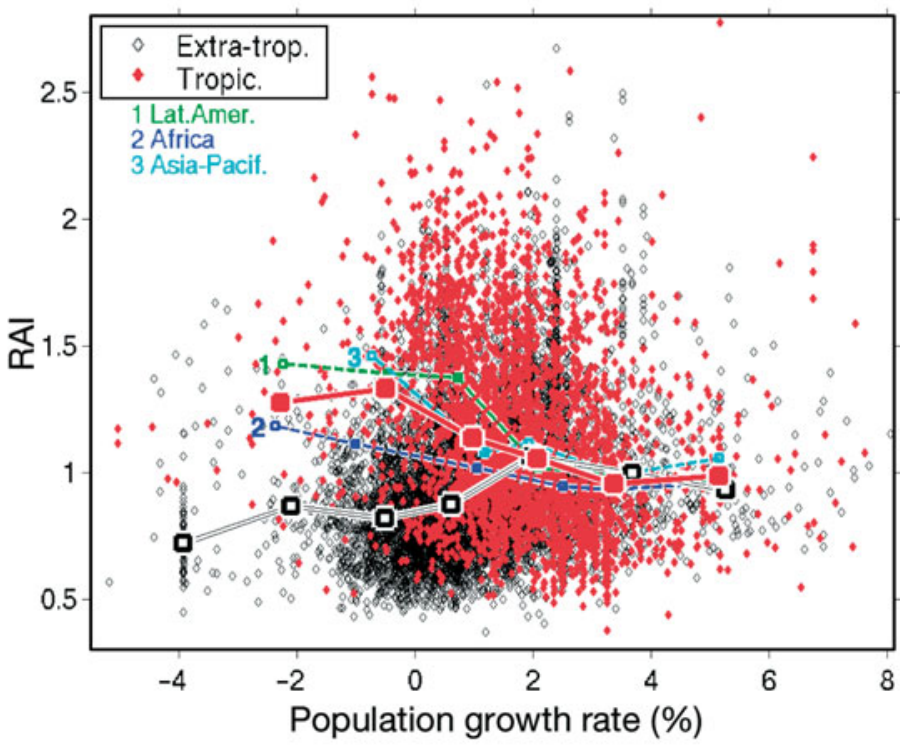

Fig. 7. Relationship between annual population growth rate (1990 to 2000) and the rainfall amplitude index (RAI). The squares correspond to the mean values obtained for successive growth rate classes. Black open symbols and the double line correspond to extratropical locations. Red symbols correspond to tropical locations. Dashed lines correspond to tropical Latin America, tropical Africa and tropical Asia/Pacific islands 
ical regions. Between 1991 and 2000, the 4 Brazilian northeastern states of Paraiba, Rio Grande do Norte, Pernambuco and Alagoas had an $11 \%$ population growth, while in the rest of Brazil it was $16 \%$. In Mauritania, annual rural growth rates between 1970 and 1990 have been as low as $0.9 \%$, compared to a West African average of over $2 \%$, based on data from the United Nations Urbanization Prospects (United Nations 2007). High rainfall variability sometimes combines with political instability to generate low population growth rates, as in Timor and Somalia.

These slower growth rates may be attributed to 2 potential factors: a lower natural growth (especially due to a higher mortality) and/or out-migration. The data used in this study do not enable to distinguish between these 2 causes. However, there is evidence from previous studies that both factors may contribute.

Mortality associated with climatic catastrophes like droughts and tropical cyclones is a recurrent feature in low-income countries (Kidane 1989, Devereux 2002, Shultz et al. 2005), although in the last decades, national and international responses to humanitarian crises have tended to reduce fatalities. Evidence of fertility decrease as a consequence of drought has also been provided for Mali (Pedersen 1995) and Ethiopia (Ezra 2001). The increase in mortality is relatively short-lived, with no real confirmation of long-term effects (Alderman et al. 2006, Song 2009). However, recurrent rainfall deficits may affect the natural growth, especially through malnutrition, which has a direct death toll $(50 \%$ of infant deaths worldwide are attributable to malnutrition) or increases the risk of fatal outcomes of severe diseases (Ehrhardt et al. 2006). Similarly, climate variability associated with ENSO results in epidemics in several parts of the tropics (Patz et al. 2005). As shown above and discussed by Nicholls \& Wong (1990), climate variability is higher in regions impacted by ENSO. It is therefore conceivable that regions displaying a higher probability of rainfall exceeding certain thresholds (as in part of the tropics), and where the population is more vulnerable (as in many developing countries, Hunter 2005), experience reduced natural demographic growth rates.

The other factor accounting for the relationship between rainfall variability and population is migration. It is suggested that a greater climatic risk triggers out-migration, mainly at times when a given climate hazard (such as a drought) exceeds the coping range. Demographic data analysed by Ezra (2001) for Ethiopia and by Henry et al. (2003) for Burkina Faso demonstrate a connection between out-migration and the occurrence and repetition of droughts. This process applies to several parts of West Africa (Lalou 1996, Mounkaila 2004, Faure 2005). In some cases like Ethiopia, migration from regions with unreliable rain- fall has been organised or even forced (Comenetz \& Caviedes 2002). At the scale of sub-Saharan Africa as a whole, interannual variation in the rains between 1981 and 2002 were significantly correlated with civil conflict onset (Hendrix \& Glaser 2007). The net result is cross-border refugee flows, for which it is difficult to separate climatic and political motivations. However, climate migrants generally move domestically rather than internationally (Afifi \& Warner 2008, Brown 2008).

Migration triggered by adverse climatic events may not necessarily be reflected in the data analysed in this study, since in some regions it may mostly be a ruralurban migration, therefore undetectable from aggregated district or regional statistics such as those used above. The fact that the relationship between demographic growth and rainfall variability is detected even with no prior separation of rural and urban populations gives further credit to the hypothesis of an effect of rainfall variability on population growth.

The lower growth / higher variability relationship should not be considered deterministic, and there are a number of departures to this trend, climate being in many instances a minor trigger of population dynamics. In India for instance, the north-westward gradient in higher rainfall variability (Fig. 3) is not paralleled by a decrease in the demographic growth rate, and the smallest population growth rates are actually found in the south. A variety of reasons explain this pattern (e.g. female education, health improvements). In the north, in addition to the higher natural growth rates that explain the strong population rise, the low rainfall reliability may have been partly compensated by the development of irrigation schemes. This has limited out-migration, or even encouraged in-migration, as in Haryana and Punjab. More generally, with respect to migrations, environment is never the single factor that pushes people to migrate, except in some critical situations (Auclair et al. 2001). Even disasters do not always trigger migrations (e.g. Findley 1994, Pedersen 1995, Paul 2005). Therefore, large rainfall variability does not necessarily mean slower demographic growth.

It is also assumed that climate variability does not lead to migration or demographic changes in a linear way (Kniveton et al. 2008). A study carried out in Burkina Faso shows that the interaction between long-term average climate conditions (mean annual rainfall) and yearly variations needs to be considered in order to best understand the relationship between rainfall and child mortality (Dos Santos \& Henry 2008). In the drier parts of this country, child mortality tends to increase when $<85 \%$ of the normal amount of rain falls during the year, in conjunction with malnutrition and income reduction. By contrast, the risk of child mortality is increased in the wettest rainfall region $(>900 \mathrm{~mm})$ when the rains are more abundant, possibly as a result 
of the development of vector-borne diseases (Dos Santos \& Henry 2008).

The latter study also points to the fact that the effect of rainfall variability is not restricted to dry environments. The measure of rainfall variability used in the present study is actually independent from the mean rainfall amount, thus suggesting that the relationship with population growth encompasses both dry and wet contexts. Fig. 7 provides evidence that, on average in the tropical zone, slow growth areas tend to have high rainfall variability. Although caution needs to be taken when discussing the impact of climate variability on populations, the above literature review supports this evidence. Two features are likely to explain the absence in the extra-tropics of such a negative relationship between rainfall variability and population variation: (1) the extra-tropics are dominated by developed countries, which are less dependent on agriculture and are less vulnerable to crop failures, as they have adequate resources and infrastructure to cope with the effects of rainfall variability; (2) rainfall variability itself is lower than in the tropics and does not show as large spatial contrasts as in the tropics.

As part of the discussion on human-induced climate change resulting from enhanced greenhouse gas concentrations, there is concern about a possible increase in climate variability in the coming decades. Räisänen (2002) showed that at the global scale, simulated rainfall variability in the event of doubled $\mathrm{CO}_{2}$ concentrations would generally change in proportion to mean rainfall. Some cases of rising variability, in areas expected to get stable or even decreasing rainfall amounts, are nevertheless projected, as in many subtropical regions and in tropical South America. Increased variability is a subject of concern for tropical areas where vulnerability to natural hazards is often high, as suggested by the above noted relationship between demographic growth and precipitation variability. Vulnerability levels are not fixed onceand-for-all (Ribot et al. 1996), They adjust to the socioeconomic background, as exemplified by some Masai groups in East Africa, whose high initial resilience has tended to regress (Galvin et al. 2004). By contrast, we may expect resilience to increase where, for example, reliable seasonal climate forecasts become available and appropriate preventive action is taken.

\section{CONCLUSIONS}

Using long-term precipitation series, this study demonstrates that the tropics, on average, show larger interannual variations in rainfall than the extra-tropics, for similar mean rainfall amounts. The difference is particularly noticeable in semi-arid to sub-humid environments (mean annual rainfall between 250 and $1000 \mathrm{~mm}$ ). However, the tropics also display strong contrasts. The largest amplitude in interannual rainfall variations tends to be found in regions where rainfall is highly dependent on large-scale SST variations. This includes several semi-arid monsoon regions, as well as regions most affected by shifts in Walker-type circulation, in the Pacific and Indian Ocean regions. Inland regions generally display a weaker interannual variability.

Although population densities do not show any systematic relationship with rainfall variability, I found that demographic growth rates in the recent decades have some connection with the amplitude of rainfall variations. This feature was apparent for the tropics as a whole and for each continent individually, but it did not apply to the extra-tropics. Regions showing larger interannual rainfall variability tended to have lower demographic growth rates between 1990 and 2000. The relationship between climate variability and demography is suggested to illustrate the combined effect of changes in natural demographic growth (especially enhanced mortality) and out-migration from the regions affected by recurrent precipitation hazards such as droughts or floods. Although outmigration does not necessarily arise as a result of adverse climatic events, these results tend to show that at the global scale, the net effect of tropical climate variability on population growth takes the form of a distinctive signal. This provides further significance to the affirmation by Hulme et al. (1999) that in the future, a valid assessment of climate-change impacts needs to incorporate the combined effects of humaninduced climate change and natural climate variability.

Acknowledgements. I thank the Center for International Earth Science Information Network, Columbia University, New York (CIESIN), and the Centre Population et Développement, Paris (CEPED), for the provision of population data and documentation, respectively. Useful remarks from 2 anonymous reviewers also helped to improve the manuscript.

\section{LITERATURE CITED}

Afifi T, Warner K (2008) The impact of environmental degradation on migration flows across countries. Working Paper No. 5/2008, UNU Institute for Environment and Human Security (UNU-EHS), Bonn

Alderman H, Hoddinott J, Kinsey B (2006) Long term consequences of early childhood malnutrition. Oxf Econ Pap 58: $450-474$

Auclair L, Gubry P, Picouët M, Sandron F (2001) Régulations démographiques et environnement. CEPED, Paris

Black E, Slingo J, Sperber KR (2003) An observational study of the relationship between excessively strong short rains in Coastal East Africa and Indian Ocean SST. Mon Weather Rev 131:74-94

Brohan P, Kennedy JJ, Harris I, Tett SF, Jones PD (2006) 
Uncertainty estimates in regional and global observed temperature changes: a new data set from 1850. J Geophys Res 111(d12):D12106

Brown O (2008) Migration and climate change. IOM Migration Res Ser 31. International Organization for Migration, Geneva

Brown C, Lall U (2006) Water and economic development: the role of variability and a framework for resilience. Nat Resour Forum 30:306-317

Caldwell J, Caldwell P (1992) Famine in Africa: a global perspective. In: van de Walle E, Pison G, Sala-Diakanda M (eds) Mortality and society in sub-Saharan Africa. Clarendon Press, Oxford, p 367-90

$>$ Camberlin P, Janicot S, Poccard I (2001) Seasonality and atmospheric dynamics of the teleconnection between African rainfall and tropical ocean surface temperature: Atlantic vs. ENSO. Int J Climatol 21:973-1005

CIESIN (2005) Gridded population of the world, Ver 3 (GPWv3): population density grids. Center for International Earth Science Information Network, Columbia University, Palisades, NY. Available at: http://sedac.ciesin. columbia.edu/gpw

> Comenetz J, Caviedes C (2002) Climate variability, political crises, and historical population displacements in Ethiopia. Glob Environ Change B Environ Hazard 4:113-127

Conrad V (1941) The variability of precipitation. Mon Weather Rev 69:5-11

Devereux S (2002) Famine in the twentieth century. IDS Working Paper 105. University of Sussex, Brighton

$>$ Dewar RE (2003) Rainfall variability and subsistence systems in Southeast Asia and the Western Pacific. Curr Anthropol 44:369-388

Dewar RE, Wallis JR (1999) Geographical patterning of interannual rainfall variability in the tropics and near tropics: an L-moments approach. J Clim 12:3457-3466

Dillehay TD, Kolata AL (2004) Long-term human response to uncertain environmental conditions in the Andes. Proc Natl Acad Sci USA 101:4325-4330

> Dos Santos S, Henry S (2008) Rainfall variation as a factor in child survival in rural Burkina Faso: the benefit of an event-history analysis. Popul Space Place 14:1-20

Ehrhardt S, Burchard GD, Mantel C, Cramer JP and others (2006) Malaria, anemia, and malnutrition in African children-defining intervention priorities. J Infect Dis 194: 108-114

Ellis J, Galvin KA (1994) Climate patterns and land use practices in the dry zones of east and west Africa. Bioscience 44:340-349

Ezra M (2001) Demographic responses to environmental stress in the drought- and famine-prone areas of northern Ethiopia. Int J Popul Geogr 7:259-279

Faure G (2005) Valorisation agricole des milieux de savanes en Afrique de l'Ouest: des résultats contrastés. Cah Outre Mer 58:5-24

Finan TJ, Nelson DR (2001) Making rain, making roads, making do: public and private adaptations to drought in Ceará, Northeast Brazil. Clim Res 19:97-108

Findley SE (1994) Does drought increase migration? A study of migration from rural Mali during the 1983-85 droughts. Int Migr Rev 28:539-553

Friederichs P, Paeth H (2006) Seasonal prediction of African precipitation with ECHAM4-T42 ensemble simulations using a multivariate MOS prediction scheme. Clim Dyn 27:761-786

Galvin KA, Thornton PK, Boone RB, Sunderland J (2004) Climate variability and impacts on East African livestock herders. Afr J Range Forage Sci 21:183-189
Hastenrath S, Polzin D (2003) Circulation mechanisms of climate anomalies in the equatorial Indian Ocean. Meteorol Z 12:81-93

Haug R (2002) Forced migration, processes of return and livelihood construction among pastoralists in Northern Sudan. Disasters 26:70-84

> Hendrix C, Glaser SM (2007) Trends and triggers: climate, climate change and civil conflict in sub-Saharan Africa. Polit Geogr 26:695-715

Henry S, Boyle P, Lambin E (2003) Modelling the influence of the natural environment on inter-provincial migration in Burkina Faso, West Africa. Appl Geogr 23:115-136

> Hulme M, Barrow EM, Arnell NW, Harrison PA, Johns TC, Downing TE (1999) Relative impacts of human-induced climate change and natural climate variability. Nature 397:688-691

Hunter LM (2005) Migration and environmental hazards. Popul Environ 26:273-302

Kidane A (1989) Demographic consequences of the 19841985 Ethiopian famine. Demography 26:515-522

Kniveton D, Schmidt-Verkerk K, Smith C, Black R (2008) Climate change and migration: improving methodologies to estimate flows. International Organisation for Migration, Geneva

$>$ Koster RD, Suarez MJ, Heiser M (2000) Variance and predictability of precipitation at seasonal-to-interannual timescales. J Hydrometeorol 1:26-46

Lalou R (1996) Les migrations internationales en Afrique de l'Ouest face à la crise. In: Coussy J, Vallin J (eds) Crise et population en Afrique. CEPED, Paris, p 345-373

> Le Blanc D, Perez R (2008) The relationship between rainfall and human density and its implications for future water stress in sub-Saharan Africa. Ecol Econ 66:319-336

Le Houérou HN (2006) Range and animal production in the arid lands of East Africa. Sécheresse 17:105-132

- Longley RW (1952) Measures of the variability of precipitation. Mon Weather Rev 80:111-117

Magalhaes AR (1993) Drought and policy responses in the Brazilian northeast. In Wilhite DA (ed) Drought assessment, management, and planning: theory and case studies. Springer, Dordrecht, p 181-198

McGregor GR, Nieuwolt S (1998) Tropical climatology. Wiley, Chichester

Milesi C, Hashimoto H, Running SW, Nemani RR (2005) Climate variability, vegetation productivity and people at risk. Global Planet Change 47:221-231

Mounkaila H (2004) Migration, chefferie et accès aux ressources foncières dans le canton de Torodi (ouest du Niger). Cah Outre Mer 226/227:313-326

Nicholls N (1988) El Nino-Southern Oscillation and rainfall variability. J Clim 1:418-421

> Nicholls N, Wong KK (1990) Dependence of rainfall variability on mean rainfall, latitude, and the Southern Oscillation. J Clim 3:163-170

> Osborn TJ, Hulme M (1997) Development of a relationship between station and grid-box rainday frequencies for climate model evaluation. J Clim 10:1885-1908

Patz J, Campbell-Lendrum D, Holloway T, Foley J (2005) Impact of regional climate change on human health. Nature 438:310-317

Paul BK (2005) Evidence against disaster-induced migration: the 2004 tornado in north-central Bangladesh. Disasters 29:370-385

> Pedersen J (1995) Drought, migration and population growth in the Sahel: the case of the Malian Gourma: 1900-1991. Popul Stud 49:111-126

Peel MC, Mc Mahon TA, Finlayson BL (2002) Variability 
of annual precipitation and its relationship to the El Niño-Southern Oscillation. J Clim 15:545-551

Peterson TC, Vose RS (2001) GHCN V2 - global historical climatology network. NOAA, Asheville, NC. Available at: http://lwf.ncdc.noaa.gov/oa/climate/research/ghcn/ ghongrid.html

Philippon N, Camberlin P, Fauchereau N (2002) Empirical predictability study of October-December East African rainfall. Q J R Meteorol Soc 128:2239-2256

Räisänen J (2002) $\mathrm{CO}_{2}$-induced changes in interannual temperature and precipitation variability in 19 CMIP2 experiments. J Clim 15:2395-2411

Retaillé D (1995) Sécheresse, migration, aménagement du territoire en Mauritanie. Rev Geogr Lyon 70:233-238

Ribot JC, Magalhães AR, Panagides SS (1996) Climate variability, climate change and social vulnerability in the semi-arid tropics. Cambridge University Press, New York

Ropelewski CF, Halpert MS (1987) Global and regional scale precipitation and temperature patterns associated with El Niño/Southern Oscillation. Mon Weather Rev 115: 1606-1626

Editorial responsibility: Mauricio Lima, Santiago, Chile
Shultz JM, Russell J, Espinel Z (2005) Epidemiology of tropical cyclones: the dynamics of disaster, disease, and development. Epidemiol Rev 27:21-35

Small C, Cohen JE (2004) Continental physiography, climate, and the global distribution of human population. Curr Anthropol 45:269-277

Song S (2009) Does famine have a long-term effect on cohort mortality? Evidence from the 1959-1961 great leap forward famine in China. J Biosoc Sci 41:469-491

Teklu T, von Braun J, Zaki E (1991) Drought and famine relationships in Sudan: policy implications. Res Rep 88. IFPRI, Washington, DC

United Nations (2007) World urbanization prospects: the 2007 revision. United Nations Population Division, New York. Available at: http://esa.un.org/unup

Weiss H (2003) Migrations during times of drought and famine in early colonial northern Nigeria. Stud Orient 95: $1-29$

Wisner B, Blaikie P, Cannon T, Davis I (2003). At risk: natural hazards, people's vulnerability, and disasters. Routledge, New York

Submitted: August 24, 2009; Accepted: March 1, 2010

Proofs received from author(s): April 8, 2010 